\title{
Age at diagnosis in relation to survival following breast cancer: a cohort study
}

\author{
Jasmine Brandt ${ }^{1,2^{*}}$, Jens Peter Garne ${ }^{3}$, Ingrid Tengrup ${ }^{1}$ and Jonas Manjer ${ }^{1,2}$
}

\begin{abstract}
Background: Age is an important risk factor for breast cancer, but previous data has been contradictory on whether patient age at diagnosis is also related to breast cancer survival. The present study evaluates age at diagnosis as a prognostic factor for breast cancer on a large cohort of patients at a single institution.

Methods: All 4,453 women diagnosed with breast cancer in Malmö University Hospital, Sweden between 1961 and 1991 were followed up on for 10 years with regards to breast cancer-specific mortality (BCSM) in different age groups. Corresponding relative risks (RR), with 95\% confidence intervals, were obtained using Cox's proportional hazards analysis. All analyses were adjusted for potential confounders and stratified for axillary lymph node involvement (ALNI) and diagnostic period.

Results: As compared to women aged 40 to 49 years, those who were aged under 40 (RR: 1.40; 95\% Cl: 1.04 to 1.88) and 80 or more years (RR: 1.80; $95 \%$ Cl: 1.45 to 2.25 ) had a statistically significant higher 10-year mortality rate. When adjusted for potential confounders, including stage at diagnosis, the associations only remained statistically significant for women aged 80 years or more. In the analyses stratified on ALNI, ALNI-negative women under 40 years had a statistically significant higher five-year mortality rate (RR: 2.65; 95\% Cl: 1.23 to 5.70). In the analyses stratified on diagnostic period, the positive association between women aged under 40 or aged 80 or more years and high BCSM rate remained, with statistically significant results for women aged 80 years or more in all periods.
\end{abstract}

Conclusions: Women under 40 years of age had a poor prognosis, and this association was strongest among young women with axillary lymph node negative breast cancer. An age of 80 years or more was a prognostic factor for poor survival, independent of stage at diagnosis and diagnostic period.

Keywords: Breast cancer, Survival, Age at diagnosis, Axillary lymph node status

\section{Background}

Age is an important risk factor for breast cancer, but it has also been suggested that patient age at diagnosis is related to breast cancer survival $[1,2]$. It has been proposed that young and old age may be adverse prognostic factors, but data is conflicting [3-5]. As breast cancer is the most common malignancy in women under 40 years of age and approximately one third of breast cancer is diagnosed in women aged 70 years and older, it is important to clarify the association between age at diagnosis and breast cancer survival [2]. Previous data has been

\footnotetext{
* Correspondence: jasmine.brandt@med.lu.se

'Department of Surgery, Lund University, Skåne University Hospital Malmö, Inga Marie Nilssons gata 47, SE-205 02 Malmö, Sweden

${ }^{2}$ Department of Plastic Surgery, Lund University, Skåne University Hospital

Malmö, Jan Waldenströmsgata 18, SE-205 02 Malmö, Sweden

Full list of author information is available at the end of the article
}

contradictory on whether the poor prognosis of young women exists in all stages, or only in women with small tumors and without axillary lymph node involvement (ALNI) [6-11]. Regarding the elderly, some studies have shown elderly women to have a poor outcome $[5,12,13]$, whereas a few studies did not find an association $[4,14]$ and one large study even found elderly women with ALNI-negative tumors to have a favorable outcome [15].

A potential reason as to why previous data has been conflicting may be that different cut-offs for age, as well as wide age groups have been used. Also, several studies have included only young or elderly women instead of all age categories. Furthermore, many previous studies have either consisted of small datasets or included several institutions. Follow-up time has in many studies also varied within the cohort, with the possible result that 
the patients with the longest follow-up may display spuriously low mortality rates, due to accumulated person-years.

The present cohort consists of a large unselected material of all women diagnosed with invasive breast cancer at a single institution in Sweden between 1961 and 1991. A total number of 4,453 cases were included and information was collected on clinical factors and tumor characteristics such as tumor size, ALNI, and distant metastasis [16]. The data has been followed up on through record-linkage with the Swedish Cause of Death Registry, and the entire cohort had the same follow-up time of 10 years. The large size of the cohort allowed the use of narrow age groups in the analyses, to study development over time, and stratification for other prognostic factors and diagnostic period.

The aim of the present study was to evaluate patient age at diagnosis as a prognostic factor for breast cancer on a large dataset at a single institution, and to examine the role of the factors included in stage at diagnosis (size, ALNI, and distant metastasis) and diagnostic period on this potential association.

\section{Methods}

\section{The Malmö Breast Cancer Database}

The study cohort consists of all cases of invasive female breast cancer in Malmö, Sweden, diagnosed between 1 January 1961 and 31 December 1991. They were all treated at the same institution, Malmö University Hospital, and no referrals were made to or from the hospital for patients with breast cancer. All residents in Sweden are registered by a unique 10-digit ID number. Breast cancer patients were identified by review of clinical notes and record-linkage with the Swedish Cancer Registry, forming the basis of the Malmö Breast Cancer Database. This was all completed by one surgeon, who also validated all breast cancer diagnoses by reviewing histological material, X-ray examinations, and medical records [16]. The present study was approved by the regional ethical committee in Lund, Sweden (approval number: LU-Dnr 615/2004).

\section{Clinical data and tumor characteristics}

The surgeon identifying the cases and constructing the database also collected data regarding date of diagnosis, menopausal status, height, weight, parity, laterality, tumor location, and distant metastases through medical records and the Swedish Cancer Registry. Information concerning tumor size, histological type, and ALNI was retrieved from histopathological examinations. Tumor type was classified using a modification of the World Health Organization (WHO) classification as proposed by Linell et al. [17]. ALNI was divided into positive, negative, or unknown if no axillary dissection had been performed.

\section{Age at diagnosis}

Age at diagnosis was obtained through a record-linkage between the Swedish Population Registry and the Swedish Cancer Registry. This information was available for all cases in the present study. The women were subsequently divided into six age groups: $<40$ years, 40 to 49 years, 50 to 59 years, 60 to 69 years, 70 to 79 years, and $\geq 80$ years at the time of diagnosis.

\section{Follow-up}

Follow-up was limited to 10 years following diagnosis. Two important reasons lay behind this decision; first, most recurrences and deaths from breast cancer occur within 10 years and second, patients diagnosed in the first diagnostic period accumulated a large number of person-years as compared to patients in later diagnostic periods. This would lead to spuriously low mortality rates for patients diagnosed during the first and second periods. To identify all deceased patients during the follow-up period, the cases' ID-numbers were linked to the Swedish Cause of Death Registry (up until 31 December 2007), which contains information on date of death and underlying cause of death, as well as subordinate causes of death. The primary endpoint of this study was breast cancer as the underlying cause of death.

\section{Study population}

A total of 4,453 women were diagnosed with breast cancer in Malmö during the study period (1961 to 1991). Out of these, 111 women were excluded as they obtained their breast cancer diagnosis at autopsy, 10 women were excluded due to missing information on all variables, 109 women were excluded because they had a previous diagnosis of breast cancer, and 104 women were excluded due to bilateral carcinomas. Consequently, the final study population consisted of 4,119 women.

\section{Statistical methods}

The six age groups were compared concerning clinical factors and tumor characteristics. For the subsequent analyses the age categories were evaluated in relation to both a five-year and 10-year follow-up period. The time scale for the study was date of diagnosis until death or until end of the follow-up period, giving each individual a potential maximum of five and 10 years in the analyses, respectively. Missing values in covariates were coded as a separate category. Breast cancer-specific mortality (BCSM) rate was calculated per 10,000 personyears in different categories of age. Corresponding relative risks (RR) with 95\% confidence intervals (CI) were 
obtained using Cox's proportional hazards analysis. The proportional hazards assumption was confirmed using a log-minus-log plot. Women aged 40 to 49 years at diagnosis, were used as the reference. The reason for selecting this age category was that the youngest age group contained only 164 subjects, along with the fact that it has been suggested that the potential association between age and survival is bi-modal [13]. All Cox analyses were subsequently adjusted for factors making up tumor stage; tumor size, ALNI, and distant metastases. In a third model, all analyses were also adjusted for other potential prognostic factors. First, by adjusting for one factor at a time and secondly, for all of the potential prognostic factors simultaneously. The only variable not adjusted for was menopausal status, since nearly all women in the two youngest age groups were premenopausal, whereas all patients in the three oldest age groups were postmenopausal. Subsequently, all analyses were stratified for ALNI, as well as for diagnostic period, in order to reveal whether or not delayed diagnosis could have affected the results.

It has been suggested that women under 35 years of age may have a poor prognosis [18]. This was examined in a sensitivity analysis, subdividing women under 40 years of age into two groups; under 35 years and 35 to 39 years. This analysis used the same reference group (40 to 49 years).

\section{Results}

Patient characteristics with reference to age at diagnosis Clinical factors and tumor characteristics of the six age groups are shown in Table 1. Distant metastasis at the time of diagnosis was more common with increasing age. There was considerably more missing data for the oldest age category ( $\geq 80$ years) concerning axillary lymph node status. It was more common for older women to have been regarded as unsuitable for surgery, and it was also less common for these women to have undergone an axillary dissection.

\section{Age at diagnosis in relation to survival}

Young age ( $<40$ years) was positively associated with a high BCSM in both the five-year follow-up period and in the 10-year follow-up period, although it was only statistically significant in the 10-year follow-up period (Table 2). However, the association disappeared when adjusted for stage and other potential prognostic factors. The two oldest age categories, 70 to 79 and $\geq 80$ years, had a statistically significant higher BCSM as compared to the reference group in both the five- and 10-year follow-up period. Women aged 80-years-old or more displayed the worst outcome, and this association remained statistically significant after adjustment for all potential confounders.
When adjusting for confounders one by one, the two factors that affected the results the strongest were ALNI and tumor size. ALNI decreased the youngest age category's RR from 1.34 ( $95 \%$ CI: 0.94 to 1.92 ) to 0.97 (95\% CI: 0.74 to 1.27 ) and the oldest age category's RR from 1.93 (95\% CI: 1.50 to 2.48) to 1.09 (95\% CI: 0.78 to 1.51 ) in the five-year follow-up period.

In the sensitivity analysis, women under 35 years of age ( 53 women) had an RR of 1.36 (95\% CI: 0.77 to 2.42 ) and women 35 to 39 years (111 women) had an RR of 1.36 (95\% CI: 0.89 to 2.06). In the 10-year follow-up period, women aged 35 to 39 had a statistically significant RR of 1.50 (95\% CI: 1.07 to 2.11), whereas the result for women under 35 did not reach statistical significance, with an RR of 1.23 (95\% CI: 0.75 to 2.02 ).

\section{Age at diagnosis and survival in relation to axillary lymph} node involvement

Young age ( $<40$ years) was associated with a high BCSM among ALNI-negative women in the five- and 10-year follow-up periods (Table 3, Figure 1). The association was statistically significant in the five-year follow-up period with an RR of 2.65 (95\% CI: 1.23 to 5.70). Ten-year $\mathrm{BCSM}$ rates were also high but were not statistically significant, with an RR of 1.69 (95\% CI: 0.92 to 3.09). Following adjustments for all potential factors, the point estimate among ALNI-negative women followed up on for five years was still high, but it did not reach statistical significance.

Women aged 70 to 79 years who were ALNI-negative also displayed a high BCSM. The oldest age group ( $\geq 80$ years) had a high BCSM among both ALNInegative and ALNI-positive women throughout both the five- and 10-year follow-up periods.

In the sensitivity analysis, ALNI-negative women aged 35 to 39 years (111 women) displayed a statistically significant RR of 3.50 (95\% CI: 1.59 to 7.70 ) and women under 35 years (53 women) an RR of 0.82 (95\% CI: 0.11 to 6.17) in the five-year follow-up period. Results were similar in the 10-year follow-up period.

\section{Age at diagnosis and survival in relation to diagnostic period}

In the results stratified for diagnostic period, young age ( $<40$ years) continued to be related to poor prognosis throughout the diagnostic periods in the five-year follow-up, although the results were not statistically significant (Table 4 ). The oldest age category ( $\geq 80$ years) displayed the highest BCSM in all diagnostic periods. The results were similar in the 10-year follow-up for all age categories.

Figure 2 displays the absolute risks, measured as BCSM per 10,000 person-years, which can also be found in Table 4. Mortality rates decreased for all age groups 
Table 1 Distribution of age at diagnosis in relation to patient characteristics, tumor characteristics, and surgical treatment

\begin{tabular}{|c|c|c|c|c|c|c|}
\hline \multirow[t]{3}{*}{ Factor } & \multicolumn{6}{|c|}{ Age at diagnosis (years) } \\
\hline & $<40$ & $40-49$ & $50-59$ & $60-69$ & $70-79$ & $\geq 80$ \\
\hline & $(n=164)$ & $(n=630)$ & $(n=886)$ & $(n=1062)$ & $(n=818)$ & $(n=559)$ \\
\hline
\end{tabular}

Time of diagnosis

1961-1970

1971-1980

1981-1991

Menopausal status

Premenopausal

Postmenopausal

Body Mass Index

$<20$

$20-<25$

$25-<30$

$\geq 30$

Missing

Parity (number of children)

Nullipara

1

2

3

$\geq 4$

Unknown

Size of primary tumor (millimeters)

$<5$
$5-\leq 10$
$10-\leq 20$
$20-\leq 50$
$>50$
Missing

Histological type

Tubular

Tubulo-ductal

Comedo

Lobular

Invasive, variable, unknown

Invasive, type not assessed

Tumor location

Upper inner quadrant

Lower inner quadrant

Upper outer quadrant

Lower outer quadrant

Central

Missing
31

23$$
5
$$

2

\section{2}

9

30

31

2

26

4

34
34
33

29

39

32

21

79

10

11

43

16

4

26

\section{0}

$$
25
$$

29
39
32
21
79
6
37
20
8
29

\section{6}

37

20

8

29

\section{1}

27

31

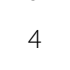

4

\section{2}$$
12
$$

$$
29
$$$$
25
$$$$
3
$$$$
29
$$

29

\section{8}

\section{4}

16

26
36
38

23

20

32

48

42

0

0

0

100

100

100

\section{5}

26

26

10

33

\section{6}

\section{5}

55

28

16

16

12

7

10

27

$$
6
$$

9

9

\section{1}

$$
7
$$


Table 1 Distribution of age at diagnosis in relation to patient characteristics, tumor characteristics, and surgical treatment (Continued)

\begin{tabular}{|c|c|c|c|c|c|c|}
\hline \multicolumn{7}{|l|}{ Axillary lymph node status } \\
\hline Negative & 51 & 50 & 49 & 55 & 46 & 22 \\
\hline Positive & 46 & 44 & 42 & 36 & 34 & 22 \\
\hline Unknown & 3 & 6 & 9 & 9 & 20 & 56 \\
\hline \multicolumn{7}{|l|}{ Distant metastasis at diagnosis } \\
\hline No & 99 & 97 & 95 & 94 & 91 & 90 \\
\hline Yes & 1 & 3 & 5 & 6 & 9 & 10 \\
\hline \multicolumn{7}{|l|}{ Type of surgery } \\
\hline Mastectomy & 85 & 87 & 84 & 81 & 84 & 64 \\
\hline Partial mastectomy/local excision & 15 & 13 & 14 & 16 & 9 & 14 \\
\hline Inoperable & 0 & 0 & 0 & 3 & 7 & 22 \\
\hline \multicolumn{7}{|l|}{ Axillary dissection } \\
\hline Yes & 98 & 94 & 92 & 91 & 81 & 44 \\
\hline No & 2 & 6 & 6 & 6 & 12 & 33 \\
\hline Inoperable & 0 & 0 & 2 & 3 & 7 & 22 \\
\hline
\end{tabular}

$\mathrm{N}=$ number of patients in each age category.

${ }^{a}$ Due to some missing values, percentages do not always add to $100 \%$.

Table 2 Age at diagnosis in relation to breast cancer-specific mortality

\begin{tabular}{|c|c|c|c|c|c|c|c|c|}
\hline & $\begin{array}{l}\text { Age at } \\
\text { diagnosis } \\
\text { (years) }\end{array}$ & Subjects & $\begin{array}{l}\text { Person- } \\
\text { years }\end{array}$ & $\begin{array}{l}\text { Breast cancer deaths } \\
\text { (all deaths) }\end{array}$ & $\begin{array}{l}\text { Breast cancer } \\
\text { mortality } / 10,000^{a}\end{array}$ & $\begin{array}{l}\text { Relative risk } \\
(95 \% \mathrm{CI})\end{array}$ & $\begin{array}{l}\text { Relative risk } \\
(95 \% \mathrm{Cl})\end{array}$ & $\begin{array}{l}\text { Relative risk } \\
(95 \% \mathrm{Cl})\end{array}$ \\
\hline \multirow{7}{*}{$\begin{array}{l}\text { 5-year } \\
\text { follow-up }\end{array}$} & $<40$ & 164 & 722 & $40(45)$ & 554 & $1.34(0.94-1.92)$ & $0.95(0.72-1.25)$ & $0.85(0.65-1.12)$ \\
\hline & $40-49$ & 630 & 2,846 & 117 (133) & 411 & 1.00 & 1.00 & 1.00 \\
\hline & $50-59$ & 886 & 3,801 & $195(226)$ & 513 & $1.25(0.99-1.57)$ & $1.08(0.88-1.33)$ & $1.07(0.87-1.31)$ \\
\hline & $60-69$ & 1,062 & 4,559 & $204(283)$ & 448 & $1.09(0.87-1.36)$ & $1.02(0.83-1.26)$ & $1.08(0.87-1.34)$ \\
\hline & $70-79$ & 818 & 3,146 & 177 (330) & 563 & $1.36(1.08-1.72)$ & $1.02(0.82-1.28)$ & $1.15(0.91-1.45)$ \\
\hline & $\geq 80$ & 559 & 1,607 & $130(378)$ & 809 & $1.93(1.50-2.48)$ & $1.32(0.96-1.83)$ & $1.53(1.08-2.16)$ \\
\hline & All & 4,119 & 16,681 & 863 (1395) & 517 & & & \\
\hline \multirow{7}{*}{$\begin{array}{l}\text { 10-year } \\
\text { follow-up }\end{array}$} & $<40$ & 164 & 1,251 & $59(66)$ & 472 & $1.40(1.04-1.88)$ & $0.96(0.77-1.20)$ & $0.89(0.71-1.12)$ \\
\hline & $40-49$ & 630 & 5,173 & $171(193)$ & 331 & 1.00 & 1.00 & 1.00 \\
\hline & $50-59$ & 886 & 6,817 & $276(337)$ & 405 & $1.22(1.01-1.47)$ & $1.11(0.94-1.32)$ & $1.08(0.91-1.28)$ \\
\hline & $60-69$ & 1,062 & 8,017 & $283(445)$ & 353 & $1.05(0.87-1.27)$ & $1.06(0.89-1.26)$ & $1.08(0.90-1.29)$ \\
\hline & $70-79$ & 818 & 5,034 & $240(543)$ & 477 & $1.37(1.12-1.66)$ & $0.99(0.82-1.21)$ & $1.10(0.90-1.35)$ \\
\hline & $\geq 80$ & 559 & 2,168 & $147(497)$ & 678 & $1.80(1.45-2.25)$ & $1.44(1.07-1.93)$ & $1.61(1.18-2.20)$ \\
\hline & All & 4,119 & 28,460 & $1,176(2081)$ & 413 & & & \\
\hline
\end{tabular}

${ }^{a}$ Breast cancer-specific mortality per 10,000 person-years.

${ }^{\mathrm{b}}$ Adjusted for tumor size, axillary lymph node status, and distant metastasis.

'Adjusted for diagnostic period, BMI, parity, tumor size, axillary lymph node status, histological type, tumor location, and distant metastasis. 
Table 3 Age at diagnosis in relation to breast cancer-specific mortality with stratification for axillary lymph node status

\begin{tabular}{|c|c|c|c|c|c|c|c|c|c|}
\hline \multicolumn{2}{|c|}{ Axillary lymph node status } & \multirow{2}{*}{$\begin{array}{l}\text { Age at diagnosis (years) } \\
<40\end{array}$} & \multirow{2}{*}{$\begin{array}{l}\text { Subjects } \\
84\end{array}$} & \multirow{2}{*}{$\begin{array}{l}\text { Person-years } \\
399\end{array}$} & \multirow{2}{*}{$\begin{array}{l}\begin{array}{l}\text { Breast cancer deaths } \\
\text { (all deaths) }\end{array} \\
11(12)\end{array}$} & \multirow{2}{*}{$\begin{array}{l}\text { Breast cancer mortality } / 10,000^{a} \\
276\end{array}$} & \multirow{2}{*}{$\begin{array}{l}\begin{array}{l}\text { Relative risk } \\
\text { (95\% Cl) }\end{array} \\
2.65(1.23-5.70)\end{array}$} & \multirow{2}{*}{$\begin{array}{l}\begin{array}{l}\text { Relative risk } \\
\text { (95\% Cl) }\end{array} \\
2.40(1.11-5.17) \\
\end{array}$} & \multirow{2}{*}{$\begin{array}{l}\begin{array}{l}\text { Relative risk } \\
\text { (95\% Cl) }\end{array} \\
1.91(0.88-4.19)\end{array}$} \\
\hline Negative & 5- year follow-up & & & & & & & & \\
\hline & & $40-49$ & 313 & 1,531 & $16(23)$ & 105 & 1.00 & 1.00 & 1.00 \\
\hline & & $50-59$ & 434 & 2,052 & $32(48)$ & 156 & $1.50(0.82-2.73)$ & $1.68(0.92-3.06)$ & $1.64(0.90-3.02)$ \\
\hline & & $60-69$ & 579 & 2,761 & $29(65)$ & 105 & $1.01(0.55-1.86)$ & $0.92(0.49-1.71)$ & $0.87(0.46-1.64)$ \\
\hline & & $70-79$ & 373 & 1,661 & $29(81)$ & 175 & $1.70(0.92-3.12)$ & $1.50(0.81-2.80)$ & $1.35(0.71-2.58)$ \\
\hline & & $\geq 80$ & 123 & 488 & $10(57)$ & 205 & $2.03(0.92-4.47)$ & $1.69(0.76-3.78)$ & $1.88(0.82-4.30)$ \\
\hline & & All & 1,906 & 8,890 & 127 (286) & 143 & & & \\
\hline & 10-year follow-up & $<40$ & 84 & 741 & $15(18)$ & 202 & $1.69(0.92-3.09)$ & $1.53(0.84-2.81)$ & $1.29(0.70-2.38)$ \\
\hline & & $40-49$ & 313 & 2,912 & $35(47)$ & 120 & 1.00 & 1.00 & 1.00 \\
\hline & & $50-59$ & 434 & 3,881 & $58(90)$ & 149 & $1.25(0.82-1.90)$ & $1.38(0.90-2.10)$ & $1.44(0.94-2.20)$ \\
\hline & & $60-69$ & 579 & 5,119 & $57(143)$ & 111 & $0.93(0.61-1.41)$ & $0.89(0.58-1.36)$ & $0.90(0.58-1.38)$ \\
\hline & & $70-79$ & 373 & 2,860 & $60(187)$ & 210 & $1.75(1.15-2.66)$ & $1.55(1.01-2.37)$ & $1.51(0.97-2.35)$ \\
\hline & & $\geq 80$ & 123 & 714 & $13(98)$ & 182 & $1.54(0.81-2.91)$ & $1.25(0.66-2.38)$ & $1.44(0.74-2.78)$ \\
\hline & & All & 1,906 & 16,228 & $238(583)$ & 147 & & & \\
\hline \multirow[t]{14}{*}{ Positive } & 5- year follow-up & $<40$ & 75 & 301 & $28(32)$ & 930 & $1.19(0.78-1.82)$ & $1.33(0.87-2.04)$ & $1.07(0.69-1.66)$ \\
\hline & & $40-49$ & 274 & 1,141 & $89(95)$ & 780 & 1.00 & 1.00 & 1.00 \\
\hline & & $50-59$ & 376 & 1,498 & 130 (139) & 868 & $1.12(0.85-1.46)$ & $1.23(0.94-1.61)$ & $1.29(0.98-1.70)$ \\
\hline & & $60-69$ & 383 & 1,526 & $128(158)$ & 839 & $1.08(0.82-1.41)$ & $1.20(0.92-1.58)$ & $1.30(0.98-1.72)$ \\
\hline & & $70-79$ & 283 & 1,059 & $86(134)$ & 812 & $1.05(0.78-1.41)$ & $1.11(0.82-1.50)$ & $1.21(0.88-1.66)$ \\
\hline & & $\geq 80$ & 124 & 383 & $47(81)$ & 1,227 & $1.60(1.13-2.29)$ & $1.38(0.96-1.98)$ & $1.68(1.14-2.25)$ \\
\hline & & All & 1,515 & 5,908 & $508(639)$ & 860 & & & \\
\hline & 10-year follow-up & $<40$ & 75 & 472 & $42(46)$ & 890 & $1.39(0.98-2.00)$ & $1.55(1.09-2.21)$ & $1.34(0.94-1.93)$ \\
\hline & & $40-49$ & 274 & 1,954 & $121(128)$ & 619 & 1.00 & 1.00 & 1.00 \\
\hline & & $50-59$ & 376 & 2,530 & 177 (198) & 700 & $1.13(0.90-1.42)$ & $1.25(0.99-1.57)$ & $1.26(1.00-1.60)$ \\
\hline & & $60-69$ & 383 & 2,461 & $174(228)$ & 707 & $1.12(0.89-1.42)$ & $1.25(0.99-1.58)$ & $1.27(1.00-1.63)$ \\
\hline & & $70-79$ & 283 & 1,580 & $112(217)$ & 709 & $1.10(0.85-1.42)$ & $1.14(0.88-1.48)$ & $1.22(0.93-1.60)$ \\
\hline & & $\geq 80$ & 124 & 523 & $53(106)$ & 1,013 & $1.54(1.11-2.13)$ & $1.30(0.93-1.81)$ & $1.61(1.13-2.28)$ \\
\hline & & All & 1,515 & 9,520 & $679(923)$ & 713 & & & \\
\hline
\end{tabular}

$\mathrm{Cl}=$ Confidence Intervals.

a Breast cancer-specific mortality per 10,000 person-years.

${ }^{\mathrm{b}}$ Adjusted for tumor size and distant metastasis.

'Adjusted for diagnostic period, BMI, parity, tumor size, histological type, tumor location, and distant metastasis. 


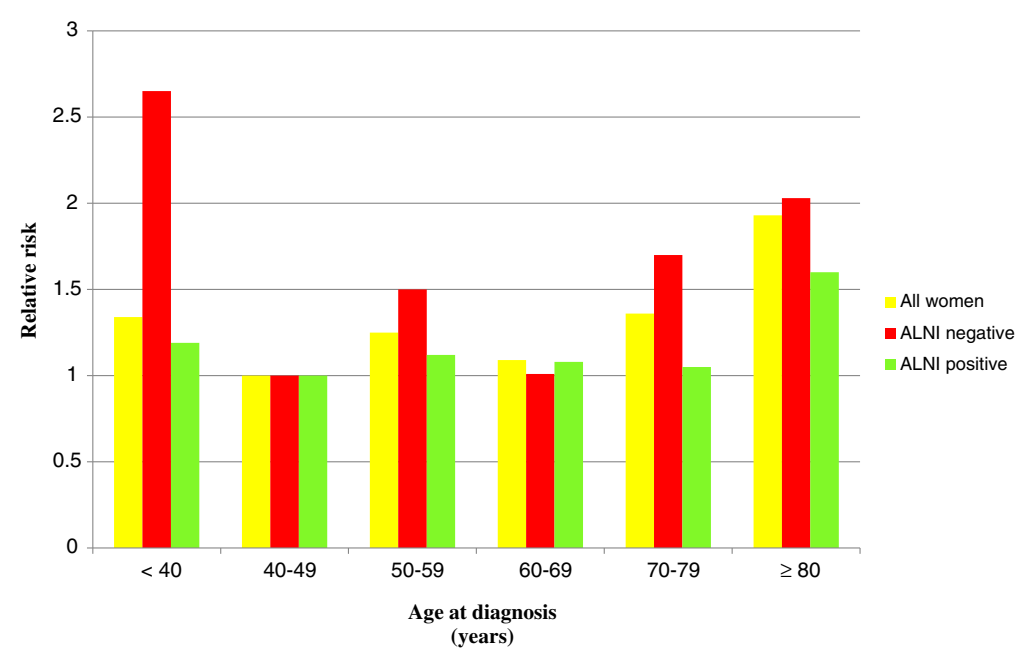

Figure 1 Age at diagnosis in relation to breast cancer-specific mortality with stratification for axillary lymph node involvement (ALNI); five-year follow-up period.

from the first to the last diagnostic period. The decrease was most apparent for women aged 50 to 59 and 60 to 69-years-old. Being diagnosed between 1981 and 1991 was associated with the best prognosis for all age categories, except for the youngest age category and the reference category, which instead had a lower BCSM in the diagnostic period 1971 to 1980 . Women aged 80 years or more continued to show a significantly higher absolute risk compared to all other age categories throughout the diagnostic periods.

\section{Discussion}

In this study, young ( $<40$ years) and old ( $\geq 80$ years) age was positively associated with a high BCSM. For women aged under 40 years, this was predominantly apparent for those with ALNI-negative breast cancer. An age of 80 years or more was a prognostic factor for high BCSM, independent of stage and diagnostic period.

\section{Strengths and limitations}

This study was conducted among women diagnosed between 1961 and 1991 and due to this some information of interest unfortunately could not be collected at the time of diagnosis. However, to our knowledge this is one of the largest population-based patient datasets with all women treated at the same institution. It consisted of 4,453 women, with a 10-year follow-up period for the entire cohort. No referrals were made to or from the hospital for patients with breast cancer. All women diagnosed with invasive breast cancer in Malmö between 1961 and 1991 were included, minimizing a potential selection bias. Age at diagnosis and breast cancer diagnosis was obtained for all patients from the Swedish Population Registry and the Swedish Cancer Registry. Both these registries are highly valid [19,20].
Histopathological examination was performed on all samples at a single pathology department; hence the reliability of tumor characteristics ought to have been high [16]. Cause of death was obtained from the Swedish Cause of Death Registry. The validity of the Swedish Cause of Death Registry has been evaluated for cause of death amongst breast cancer patients diagnosed in Malmö in two studies and found to be highly accurate $[16,21]$.

The most important data that we were not able to adjust for due to information not being collected were histological grade, hormone receptor status, and adjuvant treatment. Data on the type of operation and whether an axillary dissection was performed is displayed in Table 1 . The results were stratified for diagnostic period, which may have decreased the risk of confounding caused by treatment. In all periods adjuvant therapy was in general given routinely according to factors such as age, and ALNI; factors that were included in the analysis. This may have adjusted for treatment to some extent. However, it is still likely that older women less frequently would have been given adjuvant treatment according to the guidelines, which would have led to a lower survival rate. This is discussed further in the section below on older women. Also, women under 40 years may have been given more aggressive treatment than the guidelines indicated. For young women, it may therefore be the opposite, that is, they may have been treated more actively using, for example, chemotherapy, and their survival rate may have been even lower if we had been able to adjust for treatment.

\section{Young women}

In the present study, young age ( $<40$ years) was positively associated with high BCSM following invasive breast cancer. In the second diagnostic period (1971 to 1980) the BCSM of young women decreased and then increased 
Table 4 Age at diagnosis in relation to breast cancer-specific mortality with stratification for diagnostic period; five-year follow-up period

\begin{tabular}{|c|c|c|c|c|c|c|c|c|}
\hline $\begin{array}{l}\text { Diagnostic } \\
\text { period }\end{array}$ & $\begin{array}{l}\text { Age at } \\
\text { diagnosis } \\
\text { (years) }\end{array}$ & Subjects & $\begin{array}{l}\text { Person- } \\
\text { years }\end{array}$ & $\begin{array}{l}\text { Breast cancer deaths } \\
\text { (all deaths) }\end{array}$ & $\begin{array}{l}\text { Breast cancer } \\
\text { mortality } / 10,000^{a}\end{array}$ & $\begin{array}{l}\text { Relative risk } \\
(95 \% \mathrm{Cl})\end{array}$ & $\begin{array}{l}\text { Relative risk } \\
(95 \% \mathrm{CI})\end{array}$ & $\begin{array}{l}\text { Relative risk } \\
(95 \% \mathrm{Cl})\end{array}$ \\
\hline \multirow[t]{7}{*}{ 1961-1970 } & $<40$ & 51 & 214 & $16(18)$ & 747 & $1.39(0.79-2.45)$ & $1.69(0.96-2.98)$ & $1.23(0.69-2.20)$ \\
\hline & $40-49$ & 214 & 940 & $50(56)$ & 532 & 1.00 & 1.00 & 1.00 \\
\hline & $50-59$ & 256 & 1,008 & $82(88)$ & 813 & $1.53(1.07-2.17)$ & $1.51(1.06-2.16)$ & $1.46(1.00-2.11)$ \\
\hline & $60-69$ & 274 & 1,107 & $65(93)$ & 587 & $1.10(0.76-1.59)$ & $1.15(0.79-1.67)$ & $1.120-75-1.66)$ \\
\hline & $70-79$ & 189 & 673 & $45(92)$ & 669 & $1.25(0.83-1.86)$ & $1.33(0.88-2.02)$ & $1.35(0.87-2.09)$ \\
\hline & $\geq 80$ & 108 & 252 & $29(82)$ & 1,151 & $2.10(1.33-3.32)$ & $1.39(0.86-2.27)$ & $1.21(0.72-2.03)$ \\
\hline & All & 1,092 & 4,193 & $287(429)$ & 684 & & & \\
\hline \multirow[t]{7}{*}{ 1971-1980 } & $<40$ & 44 & 201 & $8(10)$ & 399 & $1.16(0.54-2.51)$ & $1.17(0.54-2.55)$ & $1.09(0.50-2.39)$ \\
\hline & $40-49$ & 211 & 960 & $33(39)$ & 344 & 1.00 & 1.00 & 1.00 \\
\hline & $50-59$ & 343 & 1,535 & $65(76)$ & 423 & $1.23(0.81-1.87)$ & $1.15(0.75-1.77)$ & $1.18(0.76-1.82)$ \\
\hline & $60-69$ & 386 & 1,633 & $84(116)$ & 514 & $1.49(1.00-2.23)$ & $1.65(1.09-2.48)$ & $1.69(1.11-2.57)$ \\
\hline & $70-79$ & 287 & 1,084 & $72(122)$ & 664 & $1.92(1.27-2.90)$ & $1.78(1.16-2.72)$ & $1.81(1.17-2.81)$ \\
\hline & $\geq 80$ & 181 & 518 & 44 (119) & 849 & $2.43(1.55-3.82)$ & $2.27(1.38-2.73)$ & $2.41(1.44-4.02)$ \\
\hline & All & 1,452 & 5,931 & $306(482)$ & 516 & & & \\
\hline \multirow[t]{7}{*}{ 1981-1991 } & $<40$ & 69 & 307 & $16(17)$ & 521 & $1.45(0.80-2.62)$ & $1.49(0.82-2.70)$ & $1.15(0.62-2.13)$ \\
\hline & $40-49$ & 205 & 946 & $34(38)$ & 359 & 1.00 & 1.00 & 1.00 \\
\hline & $50-59$ & 287 & 1,258 & $48(62)$ & 382 & $1.06(0.68-1.65)$ & $1.30(0.84-2.03)$ & $1.33(0.85-2.09)$ \\
\hline & $60-69$ & 402 & 1,819 & $55(74)$ & 302 & $0.84(0.55-1.29)$ & $0.85(0.55-1.31)$ & $0.90(0.58-1.41)$ \\
\hline & $70-79$ & 342 & 1,389 & $60(116)$ & 432 & $1.20(0.79-1.82)$ & $0.67(0.43-1.04)$ & $0.82(0.52-1.30)$ \\
\hline & $\geq 80$ & 270 & 837 & $57(177)$ & 681 & $1.88(1.23-2.87)$ & $0.79(0.50-1.24)$ & $1.06(0.65-1.72)$ \\
\hline & All & 1,575 & 6,557 & 270 (484) & 412 & & & \\
\hline
\end{tabular}

$\mathrm{Cl}=$ Confidence Intervals.

${ }^{a}$ Breast cancer-specific mortality per 10,000 person-years.

${ }^{b}$ Adjusted for tumor size, axillary lymph node status and distant metastasis.

${ }^{c}$ Adjusted for BMI, parity, tumor size, axillary lymph node status, histological type, tumor location, and distant metastasis.

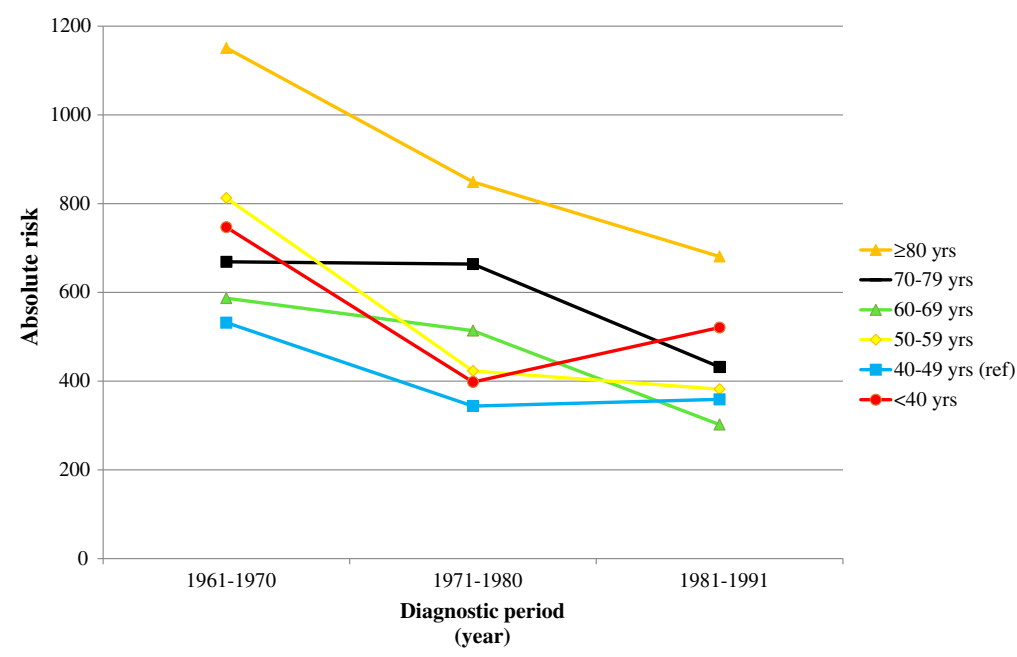

Figure 2 Age at diagnosis in relation to breast cancer-specific mortality/10,000 person-years with stratification for diagnostic period; five-year follow-up period. 
again in the following diagnostic period (1981 to 1991). However, it is difficult to interpret these small changes in BCSM as only 44 women under 40 years were diagnosed in the second period and chance may have caused some of the change.

It has been shown that young women have higher grade tumors, which are consequently more aggressive $[8,22,23]$. Tumors in young women are also more prone to be hormone receptor negative, which makes them less susceptible to respond well to adjuvant endocrine therapy such as tamoxifen $[8,23]$. Therefore the medical adjuvant therapy form for young women has instead been chemotherapy (introduced in the late 1970s at this institution) [16]. However, according to the results of this study, the BCSM of young women did not decrease in relation to other age groups in spite of the introduction of chemotherapy. Young women had the second highest BCSM in the diagnostic period 1981 to 1991, following the introduction of chemotherapy.

Several previous studies have also found young women to have a higher BCSM than other age groups [6-10,13,24-29]. However, two studies concluded that there was no difference in survival rates between young and middle-aged women [14,30]. The contradictory results may be due to breast cancer being a heterogeneous disease, with the prognostic factor age only having an effect in certain subgroups of breast cancers, such as the stage factors size, ALNI, and distant metastasis. A few previous studies have stratified for stage to evaluate this, with contradictory results. One study reported worse survival rates for young women in stages I and II [10], one large study for stages I to III [9], and one review from 2008 concluded that a worse outcome for young women is found in all stages (I to IV) [11].

Our analysis, stratified for ALNI, demonstrated that the RR increase of young women was especially apparent in ALNI-negative young women; ALNI-negative women aged under 40 years had a worse prognosis than ALNInegative women in other age categories. As ALNI status is the most important prognostic factor and women who are diagnosed as ALNI-negative are expected to have a favorable prognosis, this is an important finding. A reason for our result could be that the strong confounding factor ALNI had been stratified for, which may reveal a relatively weak prognostic factor; young age. It can also be because adjuvant treatments, such as radiotherapy, chemotherapy, and endocrine treatment, were given mainly to ALNI-positive women [16]. Consequently, the outcome in ALNI-negative women would reveal the natural course of events, where young women were distinguished as having the very worst five-year prognosis out of all age groups. In line with these findings, a previous study has shown the poor prognosis of young women is only to be found in those not treated with adjuvant therapy [29].
In the sensitivity analysis, there was no large difference in BCSM rate between women under 35 years and 35 to 39 years. However, the number of women diagnosed who were under 35 years was small (53 women), hence the statistical power of the analysis was poor.

\section{Middle-aged women}

Middle-aged women (50 to 69 years) had a worse survival rate than the reference group (40 to 49 years) in the first two diagnostic periods. However, in the last diagnostic period, starting in 1981, women aged 50 to 59 years had a similar survival rate and women aged 60 to 69 years had an even better survival rate, as compared to the reference group. Mammographic screening was introduced at this institution in 1976 in a randomized trial, inviting $50 \%$ of women aged 45 to 69 to participate [16]. We did not have information on which of the breast cancer cases were detected by mammographic screening. However, it is possible to hypothesize that this may explain some of the decrease in BCSM over the diagnostic periods, seen in women aged 50 to 59 years and 60 to 69 years in this study, as they would have been diagnosed at an earlier stage and subsequently have had a longer time from diagnosis until potential death from breast cancer (a lead time effect) [31]. On the contrary, the youngest and oldest women may still have experienced a relatively late diagnosis and, hence, a continuing higher BCSM rate. Adjuvant therapy was also introduced in the late 1970s. This may also be part of improved survival rates for middle-aged women due to the connection in time.

\section{Elderly women}

Women aged 70 to 79 years had a high BCSM until the last diagnostic period. It may be that diagnosis and treatment improved also for this age category, but slightly later than for middle-aged women.

The strongest association for all age categories was for the oldest women ( $\geq 80$ years), who had a worse outcome in all analyses. Previous studies have found contradictory results, with old age being shown to be associated with $[5,12,13,32]$, as well as not associated with $[4,14]$ a high mortality rate. One large study even found elderly women with ALNI-negative tumors to have a favorable outcome [15]. Adjustment for stage at diagnosis made the association slightly weaker in the present study, suggesting the possibility of delayed diagnosis. However, the results still remained statistically significant following adjustment for stage. Furthermore, stratification for ALNI did not have a large effect; therefore stage could not explain the entire difference in BCSM rate.

The survival rate for elderly women improved over the diagnostic periods. A reason for this may be that tumors 
in elderly women are often hormone receptor positive [15]. Hence a high percentage of this age group responds well to endocrine therapy $[33,34]$. The endocrine therapy tamoxifen was introduced in 1978 at this institution and could have contributed to this improved survival rate [16].

Although the survival rate improved for elderly women over the diagnostic periods, elderly women continued to have a higher relative risk when compared to other age categories. This could be due to elderly women potentially not receiving treatment according to the guidelines. In this material we unfortunately did not have access to data on adjuvant therapy, but we did have information on type of operation and data on whether or not an axillary dissection was performed. This indeed showed that it was more common that older women had been regarded as unsuitable for surgery and an axillary dissection was also less common in these women. Furthermore, it has been displayed in previous studies that women have not received treatment according to the guidelines, especially regarding adjuvant radiotherapy [12,15,35-38]. Other studies have also shown axillary lymph node dissection to be less frequently performed in the elderly [5,36,38]. Comorbidity can naturally lead to elderly women receiving less aggressive treatment, but studies have shown that old age is an independent risk factor for not receiving appropriate therapy after control for comorbidity [12].

\section{Conclusions}

In this study, young ( $<40$ years) and old ( $\geq 80$ years) age was positively associated with a high BCSM. For women aged under 40 years, this association was predominantly apparent for those with ALNI-negative breast cancer. An age of 80 years or more was a prognostic factor for high BCSM, independent of stage and diagnostic period.

Breast cancer is rare amongst young women, but it is still the most common malignancy in women under 40 years of age [2]. In this study, mortality in ALNInegative young women was higher than for ALNInegative women of other age categories. This motivates further studies evaluating if ALNI-negative young women have a poor prognosis.

In this study, an age of 80 years or more was a prognostic factor for high BCSM, independent of stage and diagnostic period. Approximately one third of breast cancer is diagnosed in women aged 70 years or more, and around $15 \%$ of all breast cancer occurs in women who are aged 80 years or more at the time of diagnosis [2]. With average life expectancy rising, breast cancer is likely to become increasingly frequent in elderly women [39]. Elderly women will also live longer from the time of diagnosis and subsequently have an increased risk of metastasis. Hence, it is important to make sure that elderly women also receive treatment according to the guidelines.

\section{Consent}

The current study used information in registers and clinical notes already obtained. No additional contact was taken with previous patients, out of whom many had died since their diagnosis. The Regional ethical committee in Lund, Sweden (approval number: LU-Dnr 615/2004) recommended that previous patients should be informed about the study, and the possibility to withdraw, using advertisments in local newspapers and this was done before the analyses began.

\section{Abbreviations}

ALNI: Axillary lymph node involvement; BCSM: Breast cancer-specific mortality; Cl: Confidence Intervals; RR: Relative Risk.

\section{Competing interests}

The authors declare that they have no competing interests.

\section{Authors' contributions}

JB participated in the design of the study, carried out statistical analysis and data interpretation, and drafted and edited the manuscript. JPG collected the data and constructed the Malmö Breast Cancer Database, performed quality control of data, and critically revised the manuscript. IG was involved in the study concepts, data interpretation, and in revising the manuscript. JM was involved in study design, statistical analysis, data interpretation, manuscript editing and revising, and was responsible for coordination of the project. All authors read and approved the final manuscript.

\section{Acknowledgements}

The study was conducted within the Breast Cancer Network at Lund University (BCLU). The study was supported by grants from The Ernhold Lundström Foundation, The Einar and Inga Nilsson Foundation, The Malmö University Hospital Foundation for Cancer Research, The Anna Lisa and Sven-Eric Lundgrens Foundation, The Crafoord Foundation, The Malmö University Hospital Founds and Donations, and The Mossfelt Foundation.

\section{Author details}

'Department of Surgery, Lund University, Skåne University Hospital Malmö, Inga Marie Nilssons gata 47, SE-205 02 Malmö, Sweden. ${ }^{2}$ Department of Plastic Surgery, Lund University, Skåne University Hospital Malmö, Jan Waldenströmsgata 18, SE-205 02 Malmö, Sweden. ${ }^{3}$ Department of Breast Surgery, Aalborg Hospital, Aarhus University Hospital, Skovvej 3, 9000 Aalborg, Denmark.

Received: 8 October 2014 Accepted: 23 December 2014

Published online: 07 February 2015

\section{References}

1. McPherson K, Steel CM, Dixon JM. ABC of breast diseases. Breast Cancerepidemiology, risk factors, and genetics. BMJ. 2000;321(7261):624-8.

2. Cancer Incidence in Sweden 2008. National Board of Health and Welfare. 2009. http://www.socialstyrelsen.se/publikationer2009/2009-12-1. Accessed 21 Jan 2015.

3. Yankaskas BC. Epidemiology of breast cancer in young women. Breast Dis. 2005;23:3-8.

4. Barchielli A, Balzi D. Age at diagnosis, extent of disease and breast cancer survival: a population-based study in Florence, Italy. Tumori. 2000;86(2):119-23.

5. Yancik R, Wesley MN, Ries LA, Havlik RJ, Edwards BK, Yates JW. Effect of age and comorbidity in postmenopausal breast cancer patients aged 55 years and older. JAMA. 2001;285(7):885-92.

6. Garicochea B, Morelle A, Andrighetti AE, Cancella A, Bos A, Werutsky G. [Age as a prognostic factor in early breast cancer]. Rev Saude Publica. 2009;43(2):311-7 [Article in Portuguese].

7. Nixon AJ, Neuberg D, Hayes DF, Gelman R, Connolly JL, Schnitt S, et al. Relationship of patient age to pathologic features of the tumor and prognosis for patients with stage I or || breast cancer. J Clin Oncol. 1994;12(5):888-94 
8. Fredholm H, Eaker S, Frisell J, Holmberg L, Fredriksson I, Lindman H. Breast cancer in young women: poor survival despite intensive treatment. PLoS One. 2009;4(11):e7695.

9. Maggard MA, O'Connell JB, Lane KE, Liu JH, Etzioni DA, Ko CY. Do young breast cancer patients have worse outcomes? J Surg Res. 2003;113(1):109-13.

10. Gnerlich JL, Deshpande AD, Jeffe DB, Sweet A, White N, Margenthaler JA. Elevated breast cancer mortality in women younger than age 40 years compared with older women is attributed to poorer survival in early-stage disease. J Am Coll Surg. 2009;208(3):341-7.

11. Bleyer A, Barr R, Hayes-Lattin B, Thomas D, Ellis C, Anderson B. The distinctive biology of cancer in adolescents and young adults. Nat Rev Cancer. 2008;8(4):288-98.

12. Schonberg MA, Marcantonio ER, Li D, Silliman RA, Ngo L, McCarthy EP. Breast cancer among the oldest old: tumor characteristics, treatment choices, and survival. J Clin Oncol. 2010;28(12):2038-45.

13. Sant M, Capocaccia R, Verdecchia A, Esteve J, Gatta G, Micheli A, et al. Survival of women with breast cancer in Europe: variation with age, year of diagnosis and country. The EUROCARE Working Group. Int J Cancer. 1998;77(5):679-83.

14. Crowe Jr JP, Gordon NH, Shenk RR, Zollinger Jr RM, Brumberg DJ, Shuck JM. Age does not predict breast cancer outcome. Archives of Surgery (Chicago, III: 1960). 1994;129(5):483-7. discussion 7-8.

15. Diab SG, Elledge RM, Clark GM. Tumor characteristics and clinical outcome of elderly women with breast cancer. J Natl Cancer Inst. 2000;92(7):550-6.

16. Garne JP. Invasive breast cancer in Malmö 1961-1991. Malmö: Department of Surgery, Malmö University Hospital, Sweden; 1996.

17. Linell F, Ljungberg $O$, Andersson I. Breast carcinoma. Aspects of early stages, progression and related problems. Acta Pathol Microbiol Scand Suppl. 1980:272:1-233.

18. Goldhirsch A, Glick JH, Gelber RD, Coates AS, Thürlimann B, Senn H-J. Meeting highlights: international expert consensus on the primary therapy of early breast cancer 2005. Ann Oncol. 2005;16(10):1569-83.

19. Barlow L, Westergren K, Holmberg L, Talback M. The completeness of the Swedish Cancer Register: a sample survey for year 1998. Acta Oncol. 2009:48(1):27-33.

20. Description of the population in Sweden 2008. Statistics Sweden. 2008. http:// wuw.scb.se/en_/Finding-statistics/Publishing-calendar/Show-detailed-information/? publobjid=9315++. Accessed on 21 Jan 2015.

21. Andersson I, Aspegren $K$, Janzon L, Landberg T, Lindholm K, Linell F, et al. Mammographic screening and mortality from breast cancer: the Malmö mammographic screening trial. BMJ. 1988;297(6654):943-8.

22. Anders CK, Johnson R, Litton J, Phillips M, Bleyer A. Breast cancer before age 40 years. Semin Oncol. 2009;36(3):237-49.

23. Klauber-DeMore N. Tumor biology of breast cancer in young women. Breast Dis. 2005;23:9-15.

24. Yildirim E, Dalgic T, Berberoglu U. Prognostic significance of young age in breast cancer. J Surg Oncol. 2000;74(4):267-72.

25. Jayasinghe UW, Taylor R, Boyages J. Is age at diagnosis an independent prognostic factor for survival following breast cancer? ANZ J Surg. 2005;75(9):762-7.

26. Love RR, Duc NB, Dinh NV, Quy TT, Xin Y, Havighurst TC. Young age as an adverse prognostic factor in premenopausal women with operable breast cancer. Clin Breast Cancer. 2002;2(4):294-8.

27. Gajdos C, Tartter PI, Bleiweiss IJ, Bodian C, Brower ST. Stage 0 to stage III breast cancer in young women. J Am Coll Surg. 2000;190(5):523-9.

28. Han W, Kim SW, Park IA, Kang D, Youn YK, Oh SK, et al. Young age: an independent risk factor for disease-free survival in women with operable breast cancer. BMC Cancer. 2004;4:82.

29. Kroman N, Jensen MB, Wohlfahrt J, Mouridsen HT, Andersen PK, Melbye M. Factors influencing the effect of age on prognosis in breast cancer: population based study. BMJ. 2000:320(7233):474-8.

30. Rapiti E, Fioretta G, Verkooijen HM, Vlastos G, Schäfer P, Sappino A-P, et al. Survival of young and older breast cancer patients in Geneva from 1990 to 2001. Eur J Cancer. 2005;41(10):1446-52.

31. Shapiro S, Goldberg JD, Hutchison GB. Lead time in breast cancer detection and implications for periodicity of screening. Am J Epidemiol. 1974;100(5):357-66.

32. Adami HO, Malker B, Holmberg L, Persson I, Stone B. The relation between survival and age at diagnosis in breast cancer. N Engl J Med. 1986;315(9):559-63.
33. Bernardi D, Errante D, Gallligioni E, Crivellari D, Bianco A, Salvagno L, et al. Treatment of breast cancer in older women. Acta Oncol. 2008;47(2):187-98.

34. Valassiadou K, Morgan DA, Robertson JF, Pinder SE, Cheung KL. Successful management of elderly breast cancer patients treated without radiotherapy. World J Surg Oncol. 2007;5:62.

35. Hancke K, Denkinger MD, Konig J, Kurzeder C, Wockel A, Herr D, et al. Standard treatment of female patients with breast cancer decreases substantially for women aged 70 years and older: a German clinical cohort study. Ann Oncol. 2009;21(4):748-53.

36. Hurria A, Leung D, Trainor K, Borgen P, Norton L, Hudis C. Factors influencing treatment patterns of breast cancer patients age 75 and older. Crit Rev Oncol Hematol. 2003:46(2):121-6.

37. Mustacchi G, Cazzaniga ME, Pronzato P, De Matteis A, Di Costanzo F, Floriani I. Breast cancer in elderly women: a different reality? Results from the NORA study. Ann Oncol. 2007;18(6):991-6.

38. Gajdos C, Tartter PI, Bleiweiss IJ, Lopchinsky RA, Bernstein JL. The consequence of undertreating breast cancer in the elderly. J Am Coll Surg. 2001;192(6):698-707.

39. Population by Marital Status, Age and Sex Year 1968-2010. Statistics Sweden. 2011. http://www.statistikdatabasen.scb.se/pxweb/en/ssd/ START_BE_BE0101_BE0101A/BefolkningNy/table/tableViewLayout1/? rxid=80d31dd2-9bff-4de1-834c-1c11e3b6962f. Accessed on 22 Jan 2015.

\section{Submit your next manuscript to BioMed Central and take full advantage of:}

- Convenient online submission

- Thorough peer review

- No space constraints or color figure charges

- Immediate publication on acceptance

- Inclusion in PubMed, CAS, Scopus and Google Scholar

- Research which is freely available for redistribution 